

"Jolly Giants" by Paul Rudy
As you begin to read this article, pause for a moment to be mindful of your body sitting here... of your eyes gazing at this screen... of the natural flow of your breathing as you inhale....and exhale... of the sounds arising and passing in the space around you... of the flow of thoughts and mental images in the clear open space of your awareness. of the miraculous process of by which the meaning of the words you see on the screen before you is discerned and comprehended you continue to is discerned and compring you con the mental associations, inagey, comm mindul of the mental associations, imagery, commentary, or distractions that arise in your mind.

When we first began our study, practice, and research of mindfulness in the early ' 70 s we knew fewer than a handful of people who were involved in this path of practice. As our practice and research matured, we began to develop mindfulness-based programs in medicine, higher education, and business. In the mid '70s and early ' 80 s, we knew of no one else bringing these methods into the mainstream. Gradually over the years a groundswel of insight, interest, and research has emerged, creating a host of benefits and challenges, clarity and confusion, that inspires and confounds the modern mindfulness movement.

Our intent in composing this brief article is to offer an overview of some key perspectives on Mindfulness. For people relatively new to Mindfulness it's helpful to have a deepe understanding of the roots, shoots, and trends of mindfulness in order to have a broader view of the deeper meaning, purpose, and value of this vital practice.

These VUCA times - of Volatility, Uncertainty Complexity, and Ambiguity - are teaching us a lot about the value of mindfulness (Levey, J. and Levey, M. 2015) We are learning that it takes courage and determination to wake up - to be fully present - to keep our hearts and minds open discerningly and objectively, to care deeply, be curious, investigate, and question the nature of reality. To embrace this challenge we risk being continually surprised, frequently distressed, disappointed, confused, or overwhelmed by the joys and sorrows of our complex world, and of stepping out beyond the pale of worldviews and habituating norms that define our consensus "reality."

To the degree to which we wake up with mindfulness and learn to open our hearts and minds, the walls of our conventional, familiar, consensus view of reality become more clear, open, and transparent, revealing a deeper, vaster multidimensional, and interrelated view of the actual nature of reality than we have previously imagined. This is why what we call mindfulness meditation is traditionally known as Vipassana, or "Insight Meditation." Mindfulness gives us access to insight and the direct, non-conceptual intuitive wisdom that liberates us from our misconception regarding the nature of reality and the true nature of ourselves. While engaging in such pursuits is narrow the circle of people in our lives-work who can comprehend what we are searching for. As poet William Stafford reminds us:

"There's a thread you follow. It goes among things that change. But it doesn't change.

People wonder about what you are pursuing. You have to explain about the thread. But it is hard for others to see. While you hold it you can't get lost. Tragedies happen; people get hurt or die; and you suffer and get old. Nothing you do can stop time's unfolding. You don't ever let go of the thread."

While mindfulness is certainly widely adopted and practiced, our experience is that surprisingly few people are aware of its deep roots and origins in wisdom traditions-its more profound meanings, value, highest implications, and most intriguing applications. Our intent here is to offer insight, inspiration, and illumination on these facets of the jewel of mindfulness as it shines out in our modern times.

\section{Roots of Mindfulness:}

Mindfulness as a technical term has its historical origins in the ancient Pali word sati used by the Buddha in his teaching on mindfulness 
over 2600 years ago. Sati literally translates as "memory" -- as in remembering what you are paying attention to in the present moment of awareness. In an attempt to meaningfully translate treasured Buddhist meditation manuals, the English translator Rhys Davids, was the first to offer an English translation using "mindfulness" in 1881, and by 1910 mindfulness had become the generally accepted norm. Davids was inspired to use the term "mindfulness" by its use in an Anglican prayer that says, "Always be mindful of the needs of others." Interestingly, from this initial choice to translate sati as mindfulness, there is an implication that mindfulness is also akin to a newly emerging meme of "kindfulness" which reminds us that we pay attention to what we care about. The widespread day where we find the meaning of mindfulness continuing to be adapted, as it is incorporated into common use with an ever expanding variety of mindfulness-based interventions (MBIs) that are emerging within health science, corporate, and high-performance arenas of contemporary culture. Unfortunately, the meaning of the term mindfulness is also becoming increasingly misconstrued through its association with deep relaxation without mindful awareness, creative imagination visualizations, getting a good night's rest, "mindfulness chairs" mindful men's clothing or even "mindful mayonnaise" -all of which have little or nothing to do with the meditative practice of mindfulness. Some respected teachers in the realm of mindfulness have gone so far as to say that the word 'mindfulness' has all but lost its original meaning.

\section{Roots of the Modern \\ Mindfulness Revolution}

While the teachings of mindfulness practice have endured for millennia since the time of the Buddha, the contemporary "mindfulness revolution" was propelled into modern times by the colonial thrust of the British Imperial Army invadin and conquering the Buddhist kingdom of Burma on November 28, 1885 .

For centuries the Burmese people regarded their king as "the protector of the Dhamma" - the liberating teachings of the Buddha which, when taken to heart, have the power to free us of our delusions and confusions by opening our wisdom yes to directly discern things as they truly are. Mindfulness is the primary practice of these liberating teachings, and its power lies in quieting the conceptual dualistic overlay of thoughts to allow direct insight into the true nature of reality to arise clearly in the mind.

As the Brits marched into the capital city of Mandalay, the Burmese people looked on in horror as their beloved king and his family, surrounded by British soldiers brandishing rifles, were taken from the royal palace and unceremoniously loaded in a oxcart that carried them to a waiting steamship that would carry them into axile. The royal palace was then transformed into an officers' club for drinking, dancing, and socializing A profound wave of concern rippled through Burmese society giving rise to an unprecedented cultural revolution that activated the Burmese people to protect the teachings of the Dhamma. Foremost among these cherished teachings was the practice of mindfulness. Up to this time in Burma and throughout SE Asia, the teachings and practice of mindfulness had been mostly held within the monastic community of ordained monks and nuns, while the religious practices of the lay community focused primarily on generosity and giving of alms to generate spiritual merit, with the assumption that lay people were unlikely to actually realize enlightenment through practicing meditation. With the advent of the British invasion and the king's exile, visionary teachers within the monastic community, lead by Ledi Sayadaw, launched a cultural revolution intent on teaching and encouraging the practices of the Vipassana tradition of insight meditation that mindfulness comes from, to penetrate more widely throughout secular society. In the decades that followed, a contemplative cultural revolution spread throughout Southeast Asia giving rise to a renaissance and wide diffusion of mindfulness teachings. (Braun, 2014)

\section{Three Main Streams of Mindfulness Practice:}

The next wave of mindfulness revolutionaries appeared as droves of globe trotting spiritual seekers, peace core volunteers, government spooks, and mind scientists who traveled to Asia in the 1960s and 70s intent on seeking out enlightening teachers, wisdom teachings, and liberating contemplative technologies. Word of inspiring teachers and meditation retreats quickly spread through the social networks of those times drawing early wave of contemplative pilgrims to the monasteries and meditation centers of SE Asia to get their first immersive and transformative experiences of intensive mindfulness meditation practices, which were often presented in 10 day silent retreat formats or longer even more intensive retreats.

Through the influence of many of these early adopters of mindfulness, three principle streams of mindfulness practice have flowed into modern Western culture.

One stream of mindfulness practice cam to the West through the teachings of Mahasi Sayadaw, U Pandita, Buddhadāsa Bhikkhu, and other Thai and Burmese teachers of the "forest monastery" tradition which emphasized a blend of mindful breathing, noting and noticing of the nuances of momentary changing experiences, mindful walking, mindful eating, integrating mindful awareness into every activity, and resting in open clear awareness without graspin at any momentary experience. This lineage of mindfulness practice is widely referred to as "Insight Meditation" and was introduced to the West primarily through the influence of Jack Kornfield, Sharon Salzberg, and Joseph Goldstein who co-founded the Insight Meditation Society in Barre, Massachusetts in 1975. Kornfield later also co-founded the Spirit Rock Center in Marin, California in 1988 with a number of othe teachers.

The wise and creative teachings offered these two Centers alone have inspired tens of thousands of people over the past
$40+$ years, giving rise to hundreds of othe practice centers around the globe, and playing a significant role in inspiring the global diffusion of mindfulness practice into higher education, medicine, business, military, government, sports, and other arenas of modern life. Within this stream many other respected teachers, including Anagarika Munindra, Dipama, Ajahn Amaro, Ajahn Sumedho, Thannasaro Bhikkhu, Taungpulu Sayadaw, and Rina Sircar, to name but a few, have deeply inspired the diffur of mindfulness teachings throughout North America, UK, and Europe.

The second stream came to the West from the Burmese teacher $U$ Ba Khin, the Accountant General of Burma, who founded the International Meditation Society in Rangoon in 1952 where he attracted the attention of many international students and teachers. As a lay practitioner and respected lineage holder of

the vedana vipassana tradition of mindfulness practice, and also a respected accountant, $U$ B Khin accepted the invitation from the Burmese government to assume the role of Accountant General and to assume leadership in order to route out the corruption in the Burmese Treasury Department. U Ba Khin accepted this appointment with two conditions. First was that one wing of the Treasury Department would be transformed into a meditation hall where members of his staff could come and meditate at any time. Second, was that everyone on his staff at in the Treasury Department would train with him and participate in at least one intensive ten-day silent Vipassana style mindfulness

retreat. As U Ba Khin said, "I refuse to work with incompetence."

U Ba Khin's style of mindfulness practice focused on developing concentration throug single pointed concentration on the breath, and then the close application of mindfulness by scanning or "sweeping" mindful awareness slowly through the body from the top of the head to the toes, over and over again, for up to 20 hours per day, leading to a profound state of vivid mental clarity and the purification of 
embedded congestion within the gross and subtle body. In this austere and intensive style of practice there is only sitting meditation, with no mindful walking, yoga, mindful eating or other practices at all.

In his later life, U Ba Khin passed his legacy of teachings on to seven teachers including S.N. Goenka (a Burmese business man who is widely known in the West), Robert Hover (a former U.S. aeronautical engineer) Ruth Denison (a German pioneer in embodied practices), and John Coleman (a British MIG agent), each of whom carried these liberating teachings back to North America and Europe. In particular, Goenka's approach to teaching mindfulness has become very popular and widely available in the West and around the world, especially as the teachings and retreats are offered free of charge. After retreats, the students are encouraged to make donations and "play it forward" to freely fund retreats for future students.

A third stream of mindfulness teachings came to the West in part due to the U.S. invasion of Vietnam, where the monk Thich Nhat Hahn and his community were practicing and teaching mindfulness as an integral practice in their nonviolent peace work amidst the terrors of the war. As the war raged on and many of his colleagues were brutally murdered, Thay, as his students

call him, took refuge in France where he founded the Plum Village international Meditation Center, and began to teach his unique and highly accessible form of mindfulness which emphasizes the practice of mindfu breathing, mindful walking, and the repetition of meditation phrases or "gathas" that are synchronized with the inhalation and exhalation of the breath. Developing deeper ease and continuity of meditation practice, phrases such as "calming...', "smiling..." or "arriving... home help to calm and focus the mind, and quiet the tendency toward random narrative during meditation practice. Today there are hundreds of centers around the globe teaching Thay's style of mindfulness practice.
One of Thay's greatest gifts of practitioners is the encouragement to bring a gentle, heartfelt, compassionate inner smile into "smile to our sorrow" and realize that "we are more than our sorrow." This convention of smiling with practice has rapidly diffused through the networks of mindfulness instructors, and over the past 20 years has become a new norm of how mindfulness is often introduced and practiced in the West.

Beyond these three primary streams, there are other streams, lineages, and teachers who emphasize a variety of aspects or approaches to the practice, and there are also many teachers and centers that weave together teachings and practices drawn from these different traditions.

\section{Kindfulness: \\ Mindfulness Blossoms As Compassion and Lovingkindness}

"Being present with kindness and compassion is being mindful." Jon Kabat Zinn

As the practice of mindfulness deepens and matures, it flowers and fruits as engaged compassionate concern and creative altruism, embracing and responsive to the needs, not only of ourselves, but of all beings why and experience vulnerability or injustice in their lives, society, and world. As many of the foremost Western mindfulness teachers and movements have matured in their practice, the nature and tone of their teachings have warmed, shifting from a more austere and terse focus on "bare attention" and taking on a more heartfelt, though often fiercely compassionate, tone that encourages their students to blend their mindful awareness with a merciful, open hearted approach to mindfulness practice.
It is becoming increasingly more common for mindfulness teachers to expand their studies and practice of mindfulness to draw inspiration from traditions that give greater emphasis to heartfelt qualities such as gratitude, genuine friendliness, compassion, lovingkindness, self-compassion, and engaged social justice action, into mindfulness education and training. This heartwarming, compassionate impulse may be integrated into mindfulness practice simply as a gentle, merciful, inner smile as one musters the courage to look within and mindfully, whole heartedly embrace the tension, apprehension, sadness or rage found there. Or it may be intentionally cultivated as a robust practice of meditation such as lovingkindness - or metta-wishing well to ourselves, others, and all beings; or generating radiant compassion regarding and embracing the presence of suffering in our lives, relationships, and world; or activating an explicit dedication to practicing mindfulness with an intention of realizing one's true nature and highest potentials for the benefit all beings. As mindfulness matures into kindfulnes (Braum, A. 2016) on a societal level we are witnessing the emergence of more university programs that explicitly include compassion science and encourage compassion-based practices as part of their curriculums. Among the most respected programs in today's world are: Stanford University's CCARE Program (Center for Compassion and Altruism Research and Education) (http://ccare.stanford.edu) The Greater Good Science Center (http:// greatergood.berkeley.edu) connected with Stanford and UC Berkeley; University of Wisconsin's Center for Healthy Minds (http://www.investigatinghealthyminds.org/ cihmDrDavidson.html); Mind and Life Institute; and Max Planck Institute's Human Cognitive and Brain Sciences' ReSource Program (https:// www.resource-project.org/en/home.html )

\section{Mindfulness, Collective Intuitive Wisdom, \& Human Flourishing}

"The world we have made as a result of the level of the thinking we have done thus far creates problems that we cannot solve at the same level of thinking (i.e. consciousness) at which we have created them... We shall require a substantially new manner of thinking if humankind is to survive." -- Einstein

Could it be that the global surge of interest in mindfulness is an evolutionary impulse perfectly responsive to the challenges of these VUCA times? From our many years of practice, research, and work bringing mindfulness to organizations and communities around the globe, it seems that the greatest value and most highly leveraged application of mindfulness may be to follow Einstein's advice and equip individuals and innovative teams with the skills necessary to raise or refine the level of their personal and collective consciousness in order to source the intuitive wisdom and guidance necessary to bring forth breakthrough, disruptive innovations and solutions to complex global problems.

As the key to accessing the most subtle dimensions of intuitive wisdom, the greatest value of mindfulness in this age may be in its capacity to liberate us from our collective ignorance by opening our minds to the wisdom we need to flourish together in this beautiful and fragile world.

One of our most cherished visions and aspirations is to develop cohorts of altruistically motivated, sincere and disciplined individuals and teams, intent on employing mindfulness for accessing or "sourcing" insight from deeper, subtler strata of personal and collective intuitive wisdom, in order to bring forth the insights and innovations necessary to resolve the dire challenges of these treacherous times while promoting human flourishing and thriving for generations to come. (Levey, J. and Levey, M. 2008)

Subtle Energies Magazine, Volume 28, Issue 3 


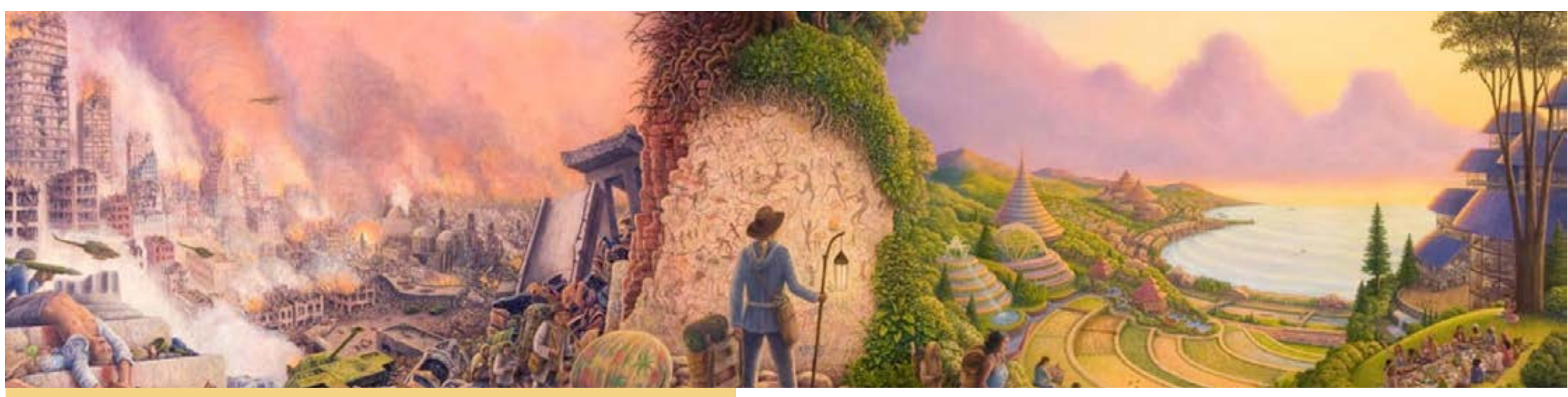

Pause for a moment to imagine that you can expand the boundless clear sky-like dimension of your mindful awareness to encompass and be aware of the inner mindstates and quality of being of all things and all beings around the world.

Imagine that you can sense the degree to which each being is awake and present, or mindless, distracted, or asleep.

Like a vast luminous topographical map of the inner states of consciousness of all beings, envision that wherever there are beings who are truly mindful and awake, there is a spike or spire of awareness or presence, and to the degree that a being is awake and their minds and hearts are open, the spire is higher and brighter.

Envision also that you can discern the groups of people who are gathered in mindful ways.... Those rare groups of people who have developed the personal and shared protocols to be fully awaken and present together.... Those sitting in meditation rooms and circles together... those who are sitting in boardrooms and in meetings within organizations such as Google, Linkedin, British Parliament... thosewho have the collective wisdom and intelligence, the capacity and dedication to really show up, to be awake and fully present together, to gather and activate all their highest, deepest, truest human resources to coalesce together in order to do the best work and make the wisest decisions that they can, in order to create ripples of benefit and blessing for all their stakeholders throughout the world at this time and rippling out to bring benefit for generations to come.

Can you imagine how rare and precious it is for a person to be awake that they are awake - to "know that they know"? To be in the presence of others who just like them are dedicated to cultivating the qualities of mind necessary to re-engineer, or re-sculpt their nervous systems to allow energy and information to stream unimpededly, and superfluidly in order to morph and evolve themselves to be -what the Buddha described unimpededly, and superfluidly in order to morph and evolve themselves to be -what the Buddha described
as a rare form of sentient being, called an Arya - one whose wisdom eyes are opening, as compared to a as a rare form of sentient being, called an Arya-one whose wisdom eyes are opening, as compared to a
"worldling", which is a being whose wisdom eyes are occluded and still closed and dominated by mindlessness, "worldling", which is a being whose wisdom eyes are occluded and still closed and dominated by mindlessness, distraction, deluded views of reality, neurotic and compulsive self-concern and selfishness. In contrast, those whose wisdom-eyes are opening have at least had a glimpse of the true nature of reality. They are dedicated to learning and practicing the skills of mindfulness necessary to continue to open their wisdom eyes, in order to directly realize the highest, deepest, truest potentials of themselves and others, and living a truly selfless way of life dedicated to helping others to awaken as well.

"New Pioneers by Mark Henson (by permission - http//markhensonart.com/politics)

\section{Mainstreaming \\ Mindfulness: Encouraging Trends}

In search of a deeper wisdom and truehearted love, thousands of seekers went to monasteries, ashrams, temples, and retreat center to study with the babas, lamas, gurus, shamans, and wisdom keepers of a myriad of indigenous and contemplative traditions in the $60 \mathrm{~s}$ and $70 \mathrm{~s}$. Some percentage of us became serious students, practitioners, researchers, and teachers of these treasured inner science traditions as they have streamed into modern Western culture.

As many of us returned to the West from Asia, out of a wish to share more widely what we had learned we made our way into graduate programs in psychology, medicine and health sciences, contemplative science, positive psychology, tech, human resources, ethnobotany, psychopharmacology etc. After graduate school, many stepped up into roles as professors, researchers, science editors for globa new papers, heads of research institutes, faculty at medical schools, teachers in public schools, leaders in HR departments in leading companies around the globe, consultants, and other influentia roles in society where we could widen the circles of our influence to help ease the stress, anxiety, confusion, overwhelm, despondency, and helplessness that are so prevalent in our society. In an inspiring recent book, Stealing Fire, Kotler and Wheal state that, "Eighteen million Americans now have a regular practice (Clarke T. C., et al. 2015), and, by the end of 2017, 44 percent of all U.S. companies will offer mindfulness training to employees (National Business Group on Health and Fidelity. 2016). Since rolling out their program, Aetna estimates that it's saved \$2,000 per employee in health-care costs, and gained $\$ 3,000$ per employee in productivity (Pinsker, J. March 10, 2015). This quantifiable return on investment helps explain why the meditation and mindfulness industry grew to nearly $\$ 1$ billion in 2015 (Wieczner, J. March 12, 2016). What had been 
the domain of seekers and swamis is now a staple of HR." (Kotler, S. and Wheal, J,. 2016)

In our work and travels with hundreds

of leading medical centers, universities, organizations, and governmental groups around the globe over the past $40+$ years we are heartened to see an ever widening diffusion of mindfulness teachings. Here are some of the most inspiring examples we have seen:

- Contemplative Science: The rapidly emerging field of contemplative science brings together the best of technology, neuroscience, and inner technology inspired by the wealth of the world's wisdom traditions giving rise to innovative programs and research in hundreds of universities and respected institutes around the globe. Mind Contemplative Studies have brought togethe thousands of people from around the world to share their research on mindfulness and many other contemplative practices. (https://www. imconsortium.org)

- Leadership and Contemplative Science: While a myriad of leadership developments are being offered in our world today, few have seriously addressed the development of moral, ethical, and contemplative capacities of leaders. One of the most relevant a of the most relevant and inspiring initiatives we have seen in this regard is the Mind and Life Institute's Academy for Contemplative and Ethical Leadership (ACEL) that we were fortunate to help birth. (https://www.mindandlife.org/legacyprograms/acel/ )

The ACEL charter states,

"In this time of disruption-unprecedented social and ecological change-many hunger for leadership marked by the consciousness, conscience, and capacity to catalyze and influence the larger systemic changes now needed. This is the time to focus on individual leaders in the context of a deeper understanding of how teams, organizations and networks can shift a larger social field.
"The purpose of the Academy for Contemplative and Ethical Leadership is to seed a new field of inquiry, practice, study, and research that can advance understanding of the role of contemplative practices and mindfulness in leadership for our time."

The charter of ACEL is to explore: "The role of contemplative practices-individual and collective - in the cultivation of empathy, compassion and ethics in leadership formation; the role of contemplative practices in the formation of collective intelligence, creativity, innovation, and authentic commitment for the long haul; and how contemplative practices, both individual and collective, may play key roles in moving the social field from familiar dysfunctional patterns, and giving form to more life-enhancing patterns on behalf of the common good."

Can you imagine how different our lives and world would be if all leaders in our world had the opportunity to engage in such a deep, transformational development of mindfulness before they step into positions of power?

- Mindful Law: Nearly a decade ago Rhonda McGee took a bold step to introduce the first course on Mindfulness in Law class at Berkeley followed followed her lead with programs on Mindfulness and Contemplative Lawyering as essential skills for professionals in the judicial system.

- Mindfulness in Medicine: Mindfulness is an essential element of the core curriculum within the 70+ medical schools that participate in the Consortium of Academic Health Centers for Integrative Medicine. (https://www.imconsortium. org)

Mindfulness in Government: In recent years, British Parliament's Mindfulness Roundtable which involved over $120 \mathrm{MPs}$ and Lords from different parties of the government who have trained in mindfulness, gave rise to the development of the Mindfulness Initiative and the Mindful Nation UK Report which encourages the

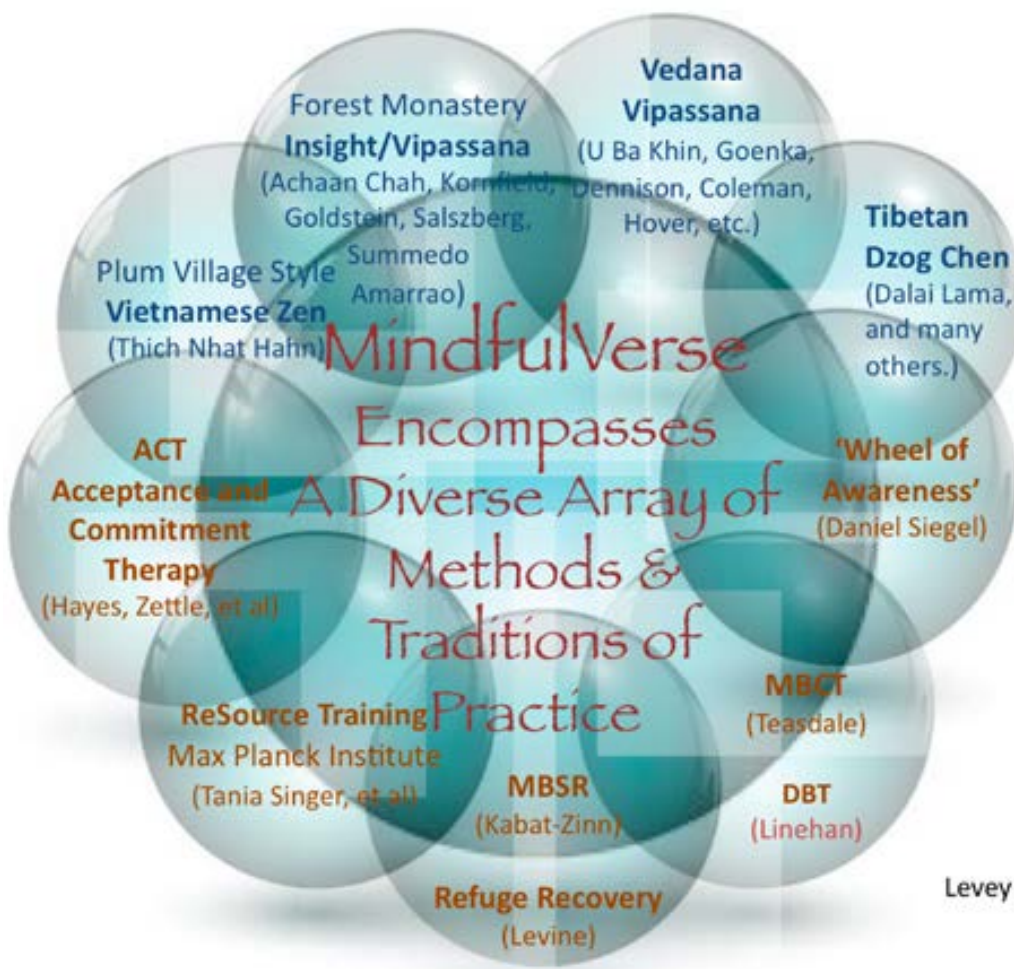

evey \& Levey, 2017

integration of mindfulness in four domains of British society: health care, education, criminal justice, an the workplace. (The Mindfulness Initiative: Mindfu Nation UK Report. 2015)

The Mindful Nation UK report articulates the concept of "mental capital," by which is meant the cognitive and emotional resources that ensure resilience in the face of stress, and the flexibility of mind and learning skills to adapt to a fast-changing employment market and longer working lives. It argues that "developing the mental capital of the nation will be crucial to our future prosperity and wellbeing.... Qualitative research shows that mindfulness develops exactly these aspects of mental capital, encouraging a curious, responsive and creative engagement to experience. This should be of real interest to policymakers given the importance of improving productivity, and nurturing creativity and innovation in the UK economy."

From recent conversation with leaders of the Mindfulness Initiative, our understanding is that leaders in seven other global governments have already launched mindfulness-based programs, seven more are seriously considering such initiatives, while representatives from anothe 35 countries have inquired about the benefits and potentials for developing similar mindfulness programs within their governments.

Subtle Energies Magazine, Volume 28, Issue 3 
- Wisdom 2.0: Since its inception in 2010, the Wisdom 2.0 conferences have brought together thousands of organizational leaders and consultants from around the planet interested in the interphase of mindfulness, meditation, yoga, leadership, innovation, organizational health and performance, social justice, quality of life, and bottom-line business results. With leaders and presenters from Google, Ford, Facebook, Twitter, LinkedIn, PayPal, Zappos, AETNA, Blackrock, Burning Man, Slack, British Parliament, U.S. Congress, and many other leading organizations to explore the many wise and helpful ways that mindfulness and related practices is delivering measurable value in our lives and world of work. (http://wisdom2conference.com About)

- Mindful Social and Emotional Learning (SEL): With an ever increasing wealth of affirming data, robust programs are integrating mindfulness with

\section{Universal Altruism} Ethical Impeccability

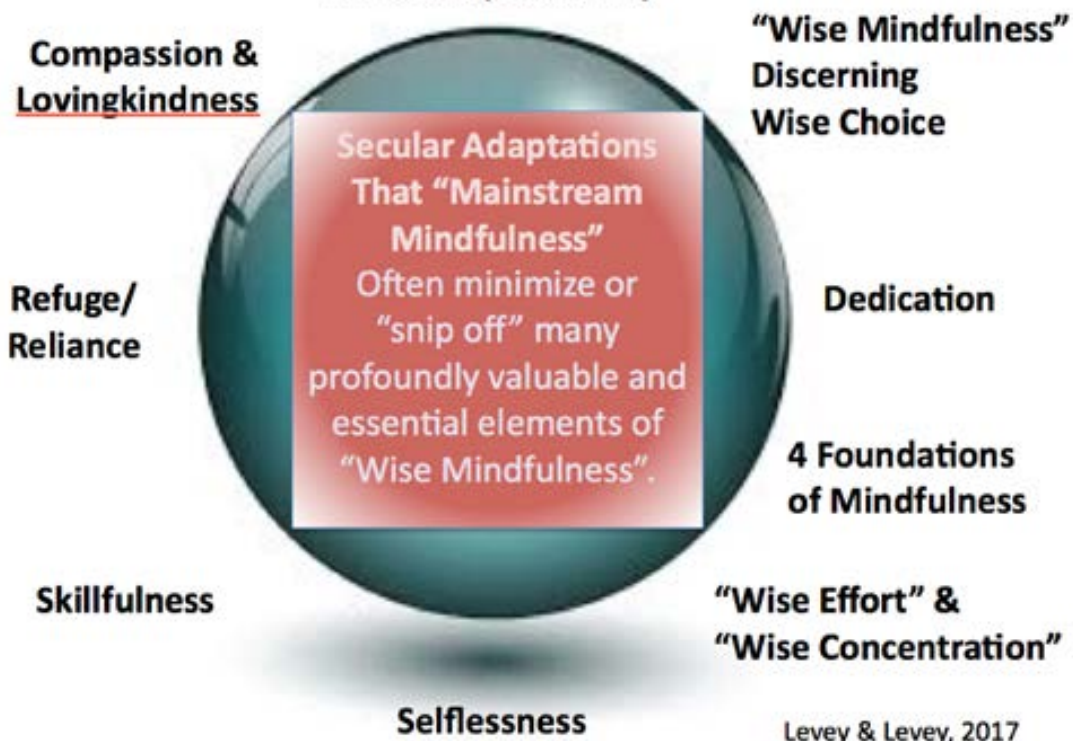

social and emotional learning into a wide array of programs around the globe.

$$
\text { From our extensive work, travels, and }
$$

research it is clear that these methods, when

properly contextualized and introduced, are

regarded as profoundly relevant, easily accessible, and able to consistently deliver inspiring personal and organizational results that are almost$$
\text { For a monthly update of compelling }
$$

research on mindfulness and mindfulness based

practices visit: http://GoAMRA.org

These are just a sampling of the significant and inspiring trends that we are seeing in the diffusion our world. primary and early childhood development learning of mindfulness into the mainstream mindstream of

ing emerged simultaneously on both coasts of the U.S. in 1978. On the East Coast, Jon KabatZinn, a molecular scientist with a deep interest in yoga and Zen, developed Mindfulness-Based Stress Reduction (MBSR) at the University of Massachusetts Medical Center. The same year, on the West Coast, Joel Levey, a psychologist, professor, and mindfulness practitioner with about 10 years of study and practice, introduced a Mindfulness and Mind-Fitness-Based Stress Mastery Program into graduate programs in Holistic Health Studies and Consciousness Studies at Antioch University, and to patients and staff at Group Health Cooperative Medical Center, a large HMO in the Seattle area. Both Kabat Zinn's and Levey's programs proved to be clinically efficacious and culturally accessible, and were readily adopted by students, clinical patients, and staff within the medical centers, universities, organizations, and communities that they served.

$$
\text { Inspired by the success of these early, }
$$

innovative, mainstreamed mindfulness programs, a wide range of MBIs (mindfulness based initiatives) and new "brands" of mindfulness training began to emerge. These MBIs include:

- Mindfulness Based Cognitive Therapy (MBCT) from John Teasdale

- Acceptance and Commitment Therapy (ACT) from Hayes, Zettle, et al.

- Wheel of Awareness from Daniel Siegel, UCLA
- Dialectical Behavioral Therapy (DBT) from Marsha M. Linehan, University of Washington ReSource Training from Tania Singer, Max Planck Institute for Human Cognitive and Brain Sciences - Refuge Recovery from Noah Levine.

\section{Important Considerations:}

When mindfulness practices are extracted from the cultural, motivational, and ethical

contexts in which they were originally developed as profoundly transformative and liberating practices, and then repurposed, reformulated, branded, commodified, or aggressively marketed for use in a secular context with the beneficial, though often narrow purposes of reducing stress, enhancing attention, or boosting performance, a host of potent potentials intrinsic to the more traditional, holistic, and spiritually significant practices are often discarded. Among the most potent contextual elements of mindfulness teachings that are most usually disregarded or "snipped off" in the Mindfulness Based Initiatives are:

- Creating a cognitive frame of reference, or reverence, that regards mindfulness as a profoundly "relational" and ennobling practice, connecting one's life, practice, and quality of being to a wider sphere of meaningful influences and interrelationships. This includes traditional practices of refuge, dedication, and explicitly Itruistic motivation in one's mindfulness practice. Such a relationally meaningful sense of dedication and purpose for one's practice expands the significance of mindfulness from a selfdevelopment practice-dedicated to reducing one's own personal distress, enhancing one's attention, or boosting productivity-to encompass a wider, more altruistic expanse. This expanded approach to mindfulness practice actively encourages developing a foundation for practice based on ethics, humankindness, cultivation of curiosity, lovingkindness (metta), compassion (and selfcompassion), generosity, altruistic motivation, and dedication. 
- The traditional holistic systems view of "wise mindfulness" within the integral liberative contex of the Noble Eightfold Path taught by the Buddha. In this comprehensive approach, "wise mindfulness" is intimately related to "wise view" regarding the actual nature of reality. When a "wise view" congruent with reality is established, then "wise intention" emerges; with "wise intention" in place, "wise speech" arises; with "wise speech" helpful "wise actions" flow; with "wise action", wise and non-harming modes of livelihood come into being; with "wise livelihood" established, "wise effort" arises which nourishes, deepens, and sustains "wise mindfulness."

To ignore or compromise any of these noble factors diminishes the wisdom and liberative power of all of them. To extract mindfulness from this framework of enlightening wisdom

that frees us from fallacious views of reality, and aligns us with the actual nature of reality, with a motivation that is in harmony with, and discerningly optimizes the circumstances of our lives and relationships, rather than creating stress or harm to ourselves, others, or our world, is to sadly miss the vital potency and extra-ordinary potential of understanding and practicing "wise mindfulness."

- Cultivating mindful discernment of those qualities of being and actions that are "wise" and to be encouraged and developed, as well as being vigilant for the arising of "unwise" sub-optimizing tendencies that are not to be encouraged or fed into. This ethically discerning approach to mindfulness provides a much broader context and meaning for mindfulness practice than a more narrow approach limited to a non-discerning "anything goes" quality of open awareness.

- The recognition of the following vital indicators of progress in mindfulness practice:

1. Becoming ever more aware of change and impermanence at subtler and subtler levels of experience;

2. A profound sense of vibrant, aware, selflessness that arises through the recognition of "wise view" revealing all things endent, interwoven, and multidimensional;

3. The recognition that any tendencies to reify or hold on to any fleeting experience will surely lead to frustration and suffering;

4. The heartfelt valuing of naturally emerging compassion regarding the suffering of confused and vulnerable beings; and

5. A deep sense of wonderment regarding the nature of reality.

While many of the secular adaptations of mindfulness include some of the elements listed above, they often fail to encourage and value the vital inclusion of these factors as an intrinsic part of the practice. While we can certainly carry on with whatever form of mindfulness practice or MBl that we are involved with, it is helpful to expand our understanding of these important considerations as we participate in the expansion of the "mindfulverse" of our modern times.

\section{Certification of}

\section{Mindfulness Teachers:}

As traditional mindfulness practices continue to be adapted for mainstream, secular use, there is an ongoing debate regarding how to establish wise quality standards and qualification for mindfulness teachers. One movement to maintain the integrity and quality of teachings has been for various universities or agencies to certify the qualification of instructors. While in theory this seems a wise strategy for preventing well-meaning, though misguided, novice practitioners from promoting themselves as qualified mindfulness teachers, such certification is often based on expensive university certification programs that emphasize the secular, therapeutic, and scientific aspects of mindfulness with less focus on understanding or practicing traditional mindfulness teachings.

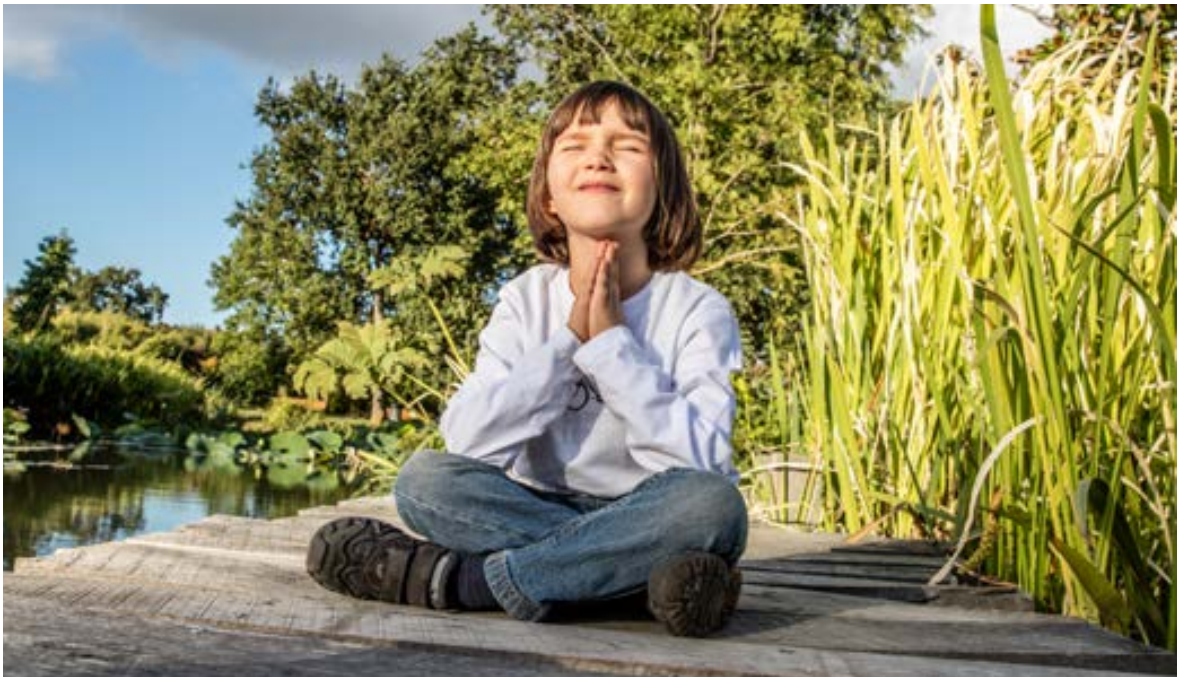

\section{Source Traditions of Mindfulness}

"What is mindfulness? Mindfulness is to be aware of everything you do every day. Mindfulness is a kind of light that shines upon all your thoughts, all your feelings, all your actions, and all your words. Mindfulness is the Buddha.

Mindfulness is the equivalent of the Holy Spirit, the energy of God.

Doing everything in our daily lives in the presence of God is mindfulness."

Thich Nhat Hanh

While the early roots of mindfulness are most clearly articulated within the Theravadan tradition of Buddhist inner science, the universa nature of mindfulness as a natural resource, is not limited to Buddhist, Asian, or modern secular variants, but has flourished and been honored throughout the ages by many of the world's great wisdom traditions.
The mystical Kabbalistic teachings of the Jewish tradition regarding the indwelling (feminine) presence of God -- the Shechina encourage practitioners to align and attune with the experience of this living universal Presence within them. Serious practitioners within this tradition devote a whole day of each week, the Sabbath, to cultivating and abiding in this sacred presence.

In mystical Christianity, mindfulness is related to "practicing the presence of God." A Sister Bernedette Roberts so eloquently observed, "Emptiness is two things at once: the absence of self and the presence of the Divine. Thus as self decreases, the Divine increases."

As mindfulness is making its way into Arabic culture, one translation for mindfulness that has emerged is, Alyagadha althehneya, which can be translated as, "Your mind being present." According to Faraz Rabbani, "Mindulness (taqwa) is to shield oneself from all that displeases Allah. The mindfulness of faith (iman) is to shield oneself from eternal punishment through faith. The mindfulness of submission (islam) is to 


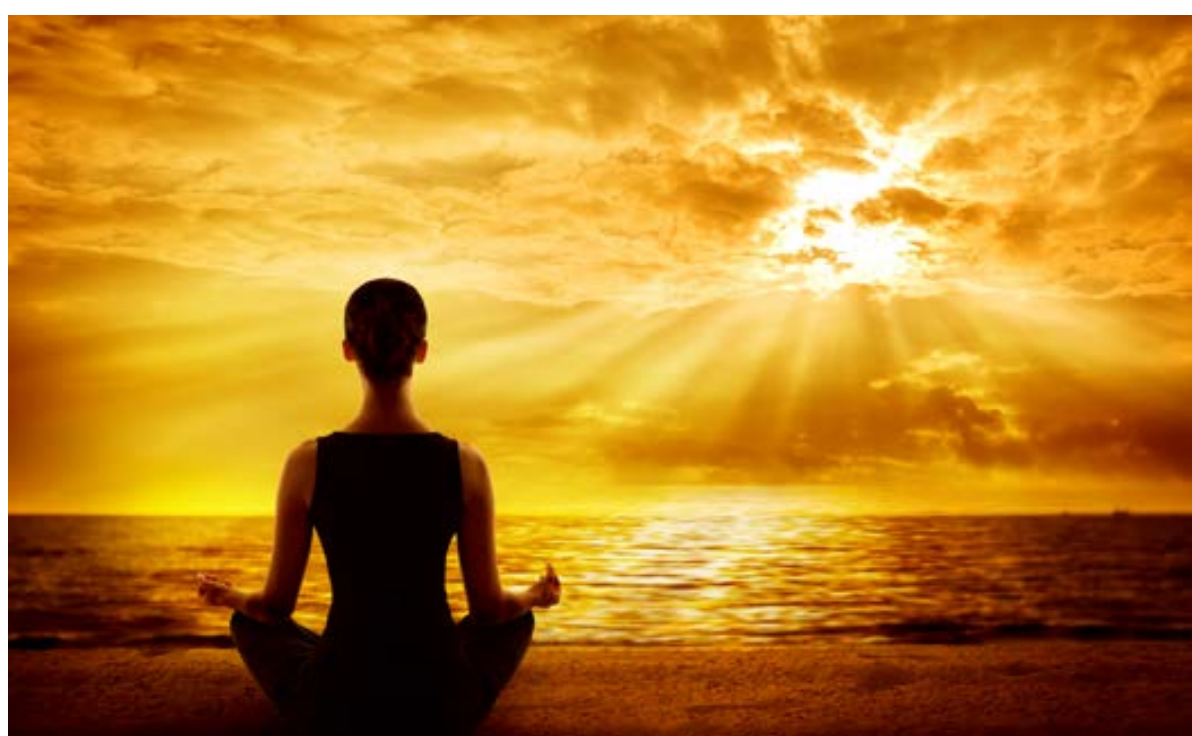

shield oneself from sin through obedience. The mindfulness of spiritua oneself from heedlessness and distraction through complete turning to Allah Most High." "Foremost of the mindful (muttaqin)" refers to being the most virtuous, honored, and beloved of Allah's servants-those of the greatest mindfulness (taqwa)."

(http://halaqah-online.com/v3/images/stories/ jalanku.jpg)

The deep nature of mindfulness is mad explicitly clear in the teachings on the nature of mind found within the Tibetan Buddhist tradition. Some years ago in London the Dalai Lama explained that "... there are two kinds of mindfulness: contrived and natural." While we can "practice" contrived mindfulness through effort and intention, "natural mindfulness" is engaged simply by remaining "naturally and gently in the essence of awareness itself." He explained that as soon as the mind is disturbed by ordinary notions and reifications, we become lost in identifying with the contents of the contrived mind. Yet underlying this ever-changing creative display of mental activity is our true nature, or home, of natural mindfulness, an elusive though accessible quality of effortless, abiding, natural awareness (rigpa) that is the ever-present dimension of awake awareness within each of us in every moment of our lives. The Dalai Lama acknowledges that this experience of natural mindfulness, or rigpa, "is beyond words, thoughts, and expression and is difficult to communicate." Echoing the Dalai Lama's wisdom, Anam Thubten, a wise and popular contemporary Tibetan teacher, offers the insight that, "Pure consciousness is present in each of us right now and we can be aware of it, but we cannot practice it or attain it. We can't attain it because it is already present within us and it's not the effect of a cause. It is not the result of our spiritual practice because it is already present in each of us. Therefore, the only thing we can do is practice being aware of it in the moment." (Thubten, A. The Magic of Awareness. 2014)

Mingyur Rinpoche offers further insight regarding this effortless approach to mindfulness, saying that, "What do we recognize? Awareness: the ever-present knowing quality of mind, from which we are never separated for an instant. Even though normally we do not recognize awareness, we can no more live without it than we can live without breathing....Discovering our own awareness allows us to access the natural steadiness and clarity of the mind, which exist independent of (ever-changing) conditions and circumstances, and independent of our emotions and moods." (Mingyur, Y. Rinpoche, and Tworkov, H. 2014)

This ancient wisdom is echoed by Jon KabatReport, when he explains that, "Basically, when we are talking about mindfulness, we are talking about awareness - pure awareness. It is an innate human capacity that is different from thinking but wholly complementary to it. It is also 'bigger' than thinking because any thought, no matter how momentous Zinn in his lucid foreword for the Mindful Nation UK or profound, illuminating or destructive, can be held in awareness, and thus looked at, known, and understood in a multiplicity of ways which may provide new degrees of insight and fresh perspectives for dealing with old problems and emergent challenges, whether individual, societal, or global..

Awareness in its purest form, or mindfulness, thus has the potential to add value and new degrees of freedom to living life fully and wisely and, thus, to making wiser and healthier, more compassionate and altruistic choices - in the only moment that any of us ever has for tapping our deep interior resources for imagination and creativity, for learning, growing, and healing, and in the end, for transformation, going beyond the limitations of our presently understood models of who we are as human beings and individual citizens, as communities and societies, as nations, and as a species." (The Mindfulness Initiative: Mindful Nation who we are as human beings and individual citizens, UK Report. 2015)

To appreciate the deep value and relevance of mindfulness, pause for a moment and imagine holding in one hand all the moments of your life when you were fully present, mindful, and vividly awake to what was going on within and around you. In these moments of mindful presence you were able to recognize options and discern wiser choices. If someone were talking to you, you were listening and attuned to the people in the conversation. If you were eating, you were aware of the tastes and textures of the food. If you were walking, you were mindful of movements, sensations, and attuned to your surroundings. If you were thinking, you were aware of the nature of your thoughts.

In your other hand, envision holding all the moments of your life when you were mindlessly going through the moves, letting habits of mindless inattention rule. In these moments of mindlessness, you relinquished the power of discernment and choice, and unconscious mindless habits dominated your life. Envision all the precious moments that passed by unnoticed, un-lived, never to be fully known.

Pause for a moment now to compare the relative balance and proportion of the moments of your precious life that you hold in each of your two hands. What thoughts, feelings or aspirations are you mindful of?

Having done this exercise with thousands of people around the globe, when people are honest with themselves, on average, most admit they are mindful only five to ten percent of the time. By extrapolation, this means that if you live to be one hundred years old you will have only been mindfully present for five or ten years of your entire life. If you have a child that is ten years old, you would have missed as much as nine years of the precious moments of the life you share. Is this good enough - or do you aspire to shift this balance? With practice, this is certainly possible!

While such reflections are humbling, when taken to heart, this kind of deep reflection helps to illuminate the profound and vital importance of mindfulness and the promise that mindfulness practice holds for reclaiming your life from the habit-demons of mindless inattention.

Mindfulness, or mindlessness, which will you choose, moment-to-moment, in the precious moments of your life to come? 
As this article comes to a close, we invite you to pause for a moment to mindfully reflect on how it has touched, inspired, or spoken to you. Notice the ideas or beliefs that have been clarified, confirmed, or challenged. Be mindful of the feelings and emotional tone of your experience, as well as any curiosities and questions that may be present for you. Are there any intentions or aspirations that you are aware of as you come to the end of this article?

$$
\text { If we have left you with a deeper }
$$
appreciation of the relevance of mindfulness, a glimpse of its more profound dimensions, or deeper insight regarding the complex issues of how mindfulness is expressed in our times, then we have succeeded in fulfilling our intentions.

And if you are motivated to begin or deepen your personal practice, or to explore the deeper waters and true nature of mindfulness, then our hearts are especially warmed and delighted.

Through the interfusion of our minds in the interdependence of our writing this article and you reading it, may ripples of inspiration and benefit extend to all beings that they too may awaken more fully to the precious moments of their lives and live with ever deepening wisdom and compassion.

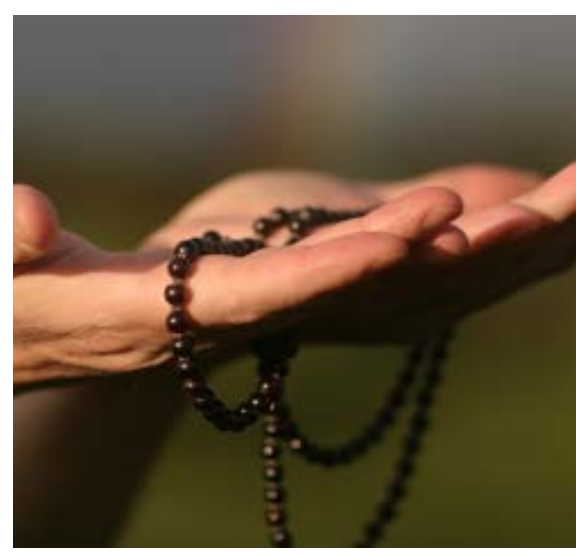

\section{Bibliography}

American Mindfulness Research Association, http:// GoAMRA.org

Bhikkhu, T. 2012. Right Mindfulness.

http://www.accesstoinsight.org/lib/authors/thanissaro/ ghtmindfulness.pdf

Braum, A. 2016. Kindfulness. Wisdom Publications.

Braun, E., Spring 2014. “Meditation En Masse: How Colonialism Sparked the Global Vipassana Movement" Tricyle. http://www.tricycle.com/feature/meditation-enmasse

Clarke T. C., et al. 2015. "Trends in the Use of Complementary Health Approaches Among Adults: United States, 2002-2012," National Health Statistics, No. 79, Hyattsville, MD, National Center for Health Statistics, 2015; "Uses of Complementar Health Approaches in the U.S." National Center for Complementary and Integrative Health.

Consortium of Academic Health Centers for Integrative Medicine. https://www.imconsortium.org

Gyatso, T. the Dalai Lama. 2001. Dzogchen: The Heart Essence of the Great Perfection. Snow Lion Publications.

Kotler, S. and Wheal, J,. 2016. Stealing Fire: How Silicon Valley, the Navy SEALs, and Maverick Scientists Are Revolutionizing the Way We Live and Work (p. 175). HarperCollins.

Levey, J. and Levey, M. 2015. Living in Balance: A Mindfu Guide for Thriving in a Complex World. Divine Arts.

https://divineartsmedia.com/products/living-in-balancea-mindful-guide-for-thriving-in-a-complex-world

Levey, J. and Levey, M. 2008. Mind Treasure. Intuition at Work. Sterling Stone Publishers.

Mind and Life Institute ACEL (Academy for Contemplative and Ethical Leadership). 2015. https://www.mindandlife. org/legacy-programs/acel/

Mind and Life Institute-Contemplative Science
Symposiums. https://www.mindandlife.org/internationalsymposium-for-contemplative-research/

The Mindfulness Initiative: Mindful Nation UK Report 2015. http://www.themindfulnessinitiative.org.uk/. publications/mindful-nation-uk-report _ and http://www. themindfulnessinitiative.org.uk

Mingyur, Y. Rinpoche, and Tworkov, H. 2014. Turning Confusion into Clarity: A Guide to the Foundation

Practices of Tibetan Buddhism (Boston: Snow Lion, 2014).

National Business Group on Health and Fidelity, July 14, 2016. Corporate Mindfulness Programs Grow in Popularity.

Pinsker, J. March 10, 2015. Corporations' Newest Productivity Hack: Meditation. Atlantic.

Purser, R., Milillo, J. 12 May 2014. Mindfulness Revisited: A Buddhist Based Conceptualization. Journa of Management Inquiry. https://www.academia.

edu/8102895/Mindfulness Revisited A Buddhist-Based Dr. Joel and Michelle Levey are founders of Wisdom Conceptualization

Thubten, A. 2012. The Magic of Aware-

ness. https://books.google.com/

books?id=tJofaSlams $Y C \&$ printsec=frontcov

er\&dq=Anam+Thubten+Thubten+magic+of+aware-

ness\&hl=en\&sa $=x \& v e d=0$ h $U K E w p$

MKHb7EAYwQ6AEIKDAA\#v $=$ onepage $\& q=$ Anam $\% 20$

Thubten\%20Thubten\%20magic\%20of\%20aware-

ness\&f=false

Wieczner, J. March 12, 2016. Meditation Has Become Billion-Dollar Business. Fortune.

Wisdom 2.0, http://wisdom2conference.com/About

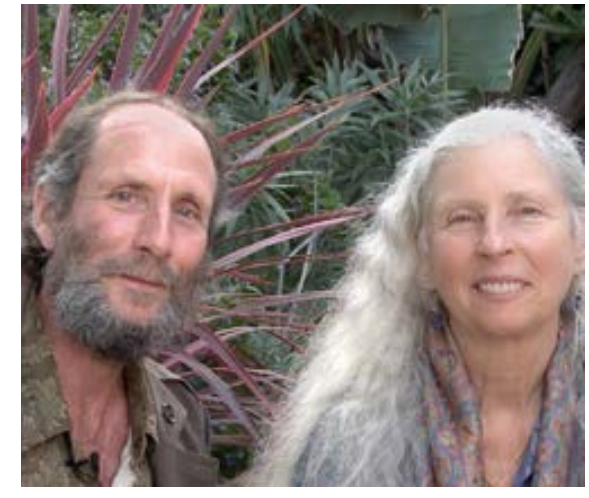
School, founding members of ISSSEEM, and early pioneers in the fields of mindfulness, contemplative science, and collective wisdom. Their seminal work has inspired leaders in hundreds of leading organizations around the globe including: NASA, Google, World Bank, Intel, British Parliament, M.D. Anderson Cancer Research Center, and the World Government Summit. They have been fortunate to study with many of the world's mave been ford respected teachers in various mindfulness lineages and other tradions of medtation, and were encouraged by many of them to teach. The Leveys' published works include: Living in Balance: A Mindful Guide for Thriving in a Complex World; Mindfulness, Meditation, and Mind Fitness; and The Fine Arts of Relaxation, Concentration and Meditation: Ancient Skills for Modern Minds. To learn more, please visit:

\section{http://WisdomatWork.com/ mindfulnesspioneers/}

